\title{
CUSTOMER SATISFACTION IN SCRM WITH KEY PERFORMANCE INDICATOR SYSTEM
}

\author{
P. Menaka ${ }^{1}$ and K. Thangadurai ${ }^{2}$ \\ ${ }^{I}$ Department of Computer Science, Manaonmaniam Sundaranar University, India \\ ${ }^{2}$ Department of Computer Science, Government Arts College, Karur, India
}

\begin{abstract}
Customer relation management is a significant feature in the business development which assists for business peoples to get the knowledge about the customer's opinions and can establish the profitable environment. Customer opinions were utilized to enhance the product, so that customer fulfilment and profit will rise desirably. So it is necessary to execute the functional design of customer opinions regarding the products which depends on the time duration. In the earlier work, Customer Knowledge Management (CKM) is established to raise the profit level of industries by tracking the entire regarding the product which is demanded by the customers. Nevertheless, creating and managing the CKM for the huge volume of the customer is a complex task. It results in inaccuracy, if in case it is done manually with less customer information. This issue is rectified in the proposed research methodology by bringing-in the methodology such as Neural Network based Social Customer Relation Management (NN-SCRM). This algorithm is utilized to examine the following factors by gathering the knowledge of the customer review information: "Predict the future, most profitable customers, maintaining quality of product development, customer life time value, identify customers and their products". This is done according to the information of the customer review, which, in turn, obtained from the customers opinions disclosed by their comments regarding the product. This proposed research work is executed and examined in the MATLAB simulation environment from which it is confirmed that the proposed research framework tends to give the best output than the current CKM frameworks.
\end{abstract}

Keywords:

Knowledge Management, Review Analysis, Pre-processing, Customer Opinions, Profit

\section{INTRODUCTION}

Customer relationship management (CRM) is significant for business integrity and profitable environment. Customer knowledge is accepted as a crucial source for any success of the organization. This knowledge adds advantage for the firm by enhancing the communication among the customer and by enhancing the opportunity to improve their creative ability via New Product development (NPD) process, which behaves like a feedback. This guessing idea utilized in CRM for providing the good performance on either sides of the organization and customers. A frame design is a core concept for creating the decision which depends on the time frame. This is termed as key performance indicator (KPI) which is utilized to enhance the company performance, process and customer satisfaction.

In designing the frame, the time and budget management is considered as a primary factor for guessing. The main manufacturing database coordinates entire process of CRM unit. According to the customer's feedback and their necessity were planned to raise the fulfilment for providing the best quality via the process and time management. In the business requirement planning, necessity of the customer was decided. The material planning provides the source material for the managing the placed order, which were received from the stock. The production planning needs to proceed with the steps for establishing the product within the time slot. The product quality is verified when finishing the product. Then the final product is proceeded for sales. The quality assurance provides a best output in satisfaction, retention and improving customers.

Through time management and scheduling, the human resource achieves knowledge and work completion in the scheduled time. This KPI assist in assuming the requirement of the customers in the future with improvement and new patterns of product. The data mining technique were utilized to find the absolute and hidden pattern in data, and it is a considerable back end process. Data mining is given as a significant CRM enabler.

In the proposed research methodology, NN-SCRM is broughtin. This algorithm is utilized to examine the following factors by gathering the knowledge of the customer review information: "Predict the future, most profitable customers, maintaining quality of product development, customer life time value, identify customers and their products". This is done according to the information of the customer review, which, in turn, obtained from the customers opinions disclosed by their comments regarding the product.

The knowledge of CRM is acquired as a customer oriented management approach where information systems give the details to favour the operational, analytical and collaborative CRM processes and also the commitment to customer profitability and retention. Whereas the probable advantages were attractive, CRM execution should be controlled cautiously to give a best output [1].

CRM analytics manages the customer relationships effectively. By utilizing the Using CRM analytics, organizations were capable of examining the nature of the customer, detect to identify customer-buying patterns and find the casual relationships. The last stage, Action, is where the strategic decisions finalized. Business processes and organizational structures were classified according to the enhanced customer acceptance acquired via analysis [2]. The last stage, Action, is where the strategic decisions finalized. Business processes and organizational structures were classified according to the enhanced customer acceptance acquired via analysis [3-5].

At the time of the current research work, it was identified that the nine literature reviews considerably on KM, which has been done in the past. It was surveyed by the authors.

The overall organization of the research work is organized as follows: In the section 2, various related works were provided, which tries to execute the effective CKM is. In section 3, proposed 
research methodology is explained in details with appropriate examples and explanation. In section 4, simulation results were provided with the simulation graphs and explanation. At last in section 5, overall research of the proposed research work is concluded according to the result which was acquired in the simulation.

\section{CUSTOMER OPINION LEARNING BASED KNOWLEDGE MANAGEMENT}

Prediction is continued from the sales process, since examining the product and customer anticipation were considered as an opinion [6]. This process assists for planning and predicting process.

The proactive solution proposes efficient output for acquiring the profit with an idea of predicting the budget [7-9]. Knowledge is a valued one for production responsibility. Knowledge Management assist an organization to acquire the intuition and acquiring the knowledge from its experience. SCRM has a prized position in the customer services and sales; it can also change the marketing strategy. Management implementation also safeguards the intellectual assets from collapse, also includes a firm intelligence and gives high flexibility. There is three guiding problems in the idea of Knowledge Management. They are: process and technology.

\subsection{PROCESS FUNCTIONAL DESIGN}

The process methodology displays a functional design with time duration. Data mining techniques were utilized to enhance the quality control in construction. In addition to the customization of time management which is established through the data mining technique. Among these three varieties of link analysis, the ordered time pattern is chosen to execute. According to this time pattern and rule induction algorithm, time track method is established. In this, six steps are explained, with plan actual date and plan description date.

Step 1: If the plan description date < the plan actual date, and plan description to date $>$ the plan actual description to date then no day difference.

Step 2: Else if plan description date < plan actual date and plan description to-date $<$ plan actual description to-date then different days are displayed.

Step 3: Else if plan actual date > To-date the day difference is zero.

Step 4: If the day difference $>0$ (exceeds the defined date) the color is set as red for the exceeded days.

Step 5: Else if the day difference $=0$ value the color is set as green. (Work completed in time)

Step 6: Else the color is set as white, if process continued.

The analog view is explained, to get the knowledge regarding the progress of the work by any programmer or person. The view is blue color which indicates the scheduled time process, and green color is the actual process time, if the process time goes beyond the scheduled time, the red color will be suggested till its completion.

\subsection{CUSTOMER SATISFACTION IN SCRM}

To enhance the performance of CKM a SCRM is presented to fulfil the customer and to improve the benefit via SCRM [10,11]. SCRM is a two way communication and reaches the feedback from the customer at periodic time interval. This in turn enhances the entire performance of the system. Because of SCRM, organizations and customers can reach various advantages, like,

- A responsibility can concentrates on community and building long term relationships with them.

- Customers are the owners of content and they manage their content.

- Communication is not only business-to customer type, but also the customer-to- customer and customer-to-prospectus.

- Customer's assist with the concern directly to indirectly in establishment and enhancement of products, services and customer support itself.

- Dialogue is less formal and more 'real', it modifies their character from the comments regarding the brand to the community.

SCRM concentrates on collaborative relationship, interaction are the value generators. SCRM strategy demands a consolidation of various ICT solutions. The heart of the SCRM strategy is interaction among the between customer and business.

The primary variation among the conventional CRM and SCRM depends on the strategy for customer's engagement; it doesn't control the customer data [12-15]. The following diagram explains the abstract framework for CKM. CRM generates various channels among the concern and potential customers and it gives personal data like biographical information. Three varieties of customer knowledge [16] are:

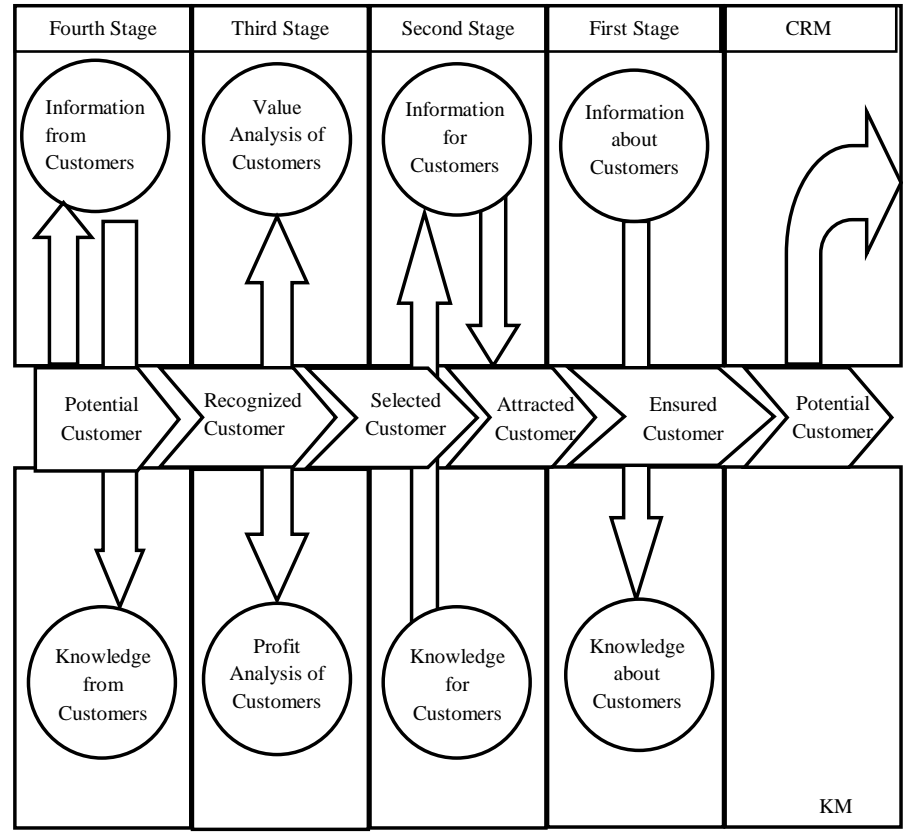

Fig.1. Proposed Conceptual Framework of CKM

Knowledge customers is accumulated to get the knowledge of the customer mush better, to identify their expectation, requirement and motivations and to mention them in an illustrated 
way; This adds customer pasts, connections requirements regarding the purchasing activity, buying habits and imbursement behaviour. Knowledge from customers is an idea that organizations gathers from its customers, this category adds, customer's common goods, sellers and markets, their concepts and approvals for considering the enhancement of the product, ideas, thoughts and material which conceives the tendency, originality or practice with products, services process or expectations. Knowledge from customers is a valuable one as it tends for calculation, which enhances the products and services $[17,18]$. Knowledge from customers is demanded to fulfil the requirement of the customers; this adds: knowledge about products, markets and suppliers, customers should be supported with "knowledge of the customer" during the entire buying cycle.

The third stage is a profit analysis which is executed in KM and CRM processes on fascinated customers. This analysis is implemented based on the developed knowledge of the transactions and merits with every customer. Mutual understanding with every customer will be lengthened only if the output acquired from the profit analysis were positive. In addition to profit analysis, value analysis is at times implemented when the output weren't positive. The fourth stage denotes the information regarding the modifications of the market the competitors' plans and strategies, people's tastes and possible enhancement which were received from valuable customers as the organization considered as active in the market.

\section{CURRENT SCENARIO OF CUSTOMER RELATIONSHIP IN BUSINESS}

The companies have changed the way of interaction with the customers badly over the past few years. So, this reduces the customer's continuing business is As a result, companies were required to identify the Customers' demands to sever them better, and to quickly respond to their needs. Besides, the time duration in which these responses were required to be done is declining [19]. It isn't feasible to wait till the signs of Customer unhappiness were accessible before action should be proceeded. To succeed, companies should be proactive and assume the customer desired thing. It is now a cliché that in these days of the corner market, shopkeepers doesn't have any problem in understanding their Customers and responding as soon as possible to their demands. The shopkeepers usually track their customers purchasing strategies in their heads, and would know what to do if customer comes to the store. But today's shopkeepers face many difficult situations. Many Customers, Many products, Many competitors, and less time to react, this will reduce the concept of understanding the customer's strategies.

\subsection{OBSTACLE IN CUSTOMER RELATIONSHIPS}

Segments of your market and adopt to save the best for themselves.

Compressed marketing cycle times: The attention span of a Customer has reduced very badly and faithfulness is a thing of the past. A successful company required to boost the value, which it contribute to its Customers in a continuous manner. Besides this, the time frame among the new aspiration and fulfilling this aspiration is also declined. If their requirement is not met soon, they will switch to the firm who will meet.
Increased marketing costs: Everything costs more. Printing, postage, special offers (and if in case we didn't give the offer, our competitors will do).

Streams of new product offerings: Customers required a product which exactly fulfil their needs, not things that sort-of fit. This means that the product's count and the ways they offered have increased considerably.

Niche competitors: Your best Customers also look good to your competitors. They will concentrate on small, profitable

Successful companies need to acknowledge to every one of these necessities in a timely fashion. Timely response is very important, else customers will move-on. Communicating with the Customers is also not easy as like past. Customers and anticipated Customers require communicating on their terms, which means that we need to look at various strategies when computing the procedure. We required automating the following:

- The Right Offer.

- To the Right Person.

- At the Right Time.

- Through the Right Channel.

The right offer is managing interactions with your Customers, programming the offers which raise the buying strategy, while making sure of reducing the inappropriate offers. The right person means that all customers aren't similar. The interaction with them required to proceed like a highly segmented marketing campaigns that target individual's requirement. The right time is a result of the fact that communication with Customers will be maintained. This is considerably different from the past, when quarterly mailings were cutting-edge marketing. At last, the right channel means that you can communicate with your Customers in a different manner (direct mail, email, telemarketing, etc.). We are required to make sure that we are selecting the most efficient medium for a specific interaction.

\section{DATA MINING AND CRM}

Customer relationship management (CRM) is a process which maintains the communication among a company and its Customers [20]. The primary users of CRM software applications were database marketers who need to automate the process of communication with Customers.

Prospects: people who are not the Consumers yet but are in the target market

Responders: prospects who show an interest in a product or service

Active Consumers: people who are currently utilizing the product or service

Former Consumers: may be "bad" Consumers who has not yet paid their bills or who provoked high costs 


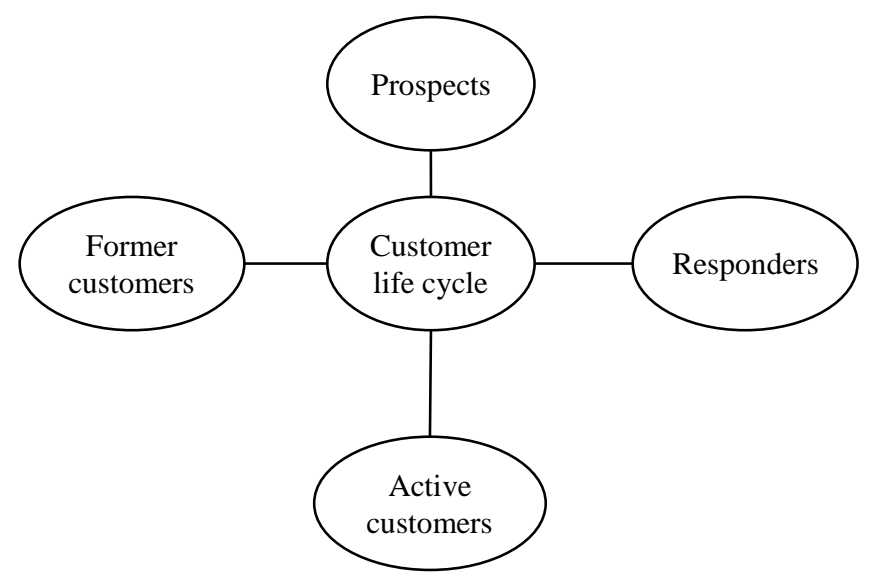

Fig.2. Key stages in the Customer Life Cycle

\subsection{NEURAL NETWORK BASED CLASSIFICATION}

Data mining in Customer relationship management applications can provide considerably to the core idea. Instead of contacting a prospect or Customer in a specific order via a call centre or sending mail, a company can focus its attempts on prospects which were anticipated to have a high possibility of responding to an offer. Many matured methods were utilized to improve the resources over the campaigns, so that one can anticipate which channel and which offer an individual will respond soon, over all potential offers. Furthermore, matured applications could be utilized to automate the mailing. If the output from data mining (potential prospect/Customer and channel/offer) were defined, this "sophisticated application" can either mechanically send an e-mail or regular mail. At last, if in cases where many people will proceed without an offer, uplift modelling can be utilized to define which people have higher possibility in responding for an offer. Data clustering can also be utilized to mechanically find the segments or groups within a Customer data set .Businesses which enforces the data mining technique to get a return on investment, but also they identify that the number of predictive models can quickly become a huge part. Instead of one model to anticipate which Customers will churn, a business could construct an individual model for every region and Customer type. Then rather than sending an offer to entire people who were possible to churn, it just sends offers to Customers who considerably takes an offer. And at last, it may also want to define which Customers will gain this profile over a window of time and can only send the offers to those people.

Classification is process, which utilizes the strategy to separate the Customer population into various classes with correlated business data. A class may anticipate some nature and inform their mode of payment. When new Customer arrives, it is likely to anticipate buying and payment behaviour of the Customer by detecting its class. In our work neural network based classification is utilized to estimate the behaviour of customers in SCRM.

Each and every one can see that the human brain is better to a computer at different tasks. A better sample is the processing of visual data: a 1-year-old kid is immensely enhanced and quicker at observing the articles, so, it is better than the most matured AI system which runs on the supercomputer. Hence, brain has a lot of several other features which is a benefit for artificial systems. This is the actual encouragement for studying neural calculation. This is a alternate idea to the common one (based on a programmed instruction order), that was brought-in by von Neumann and hare being utilized as the resource of nearly entire machine computation. It is stimulated by the knowledge from neuroscience; nevertheless it doesn't try to be naturally reasonable in detail. Neural systems provide a way to estimate that includes generating the numerical structures with the capability to learn. The techniques were the result of scholastic examinations to model nervous system learning. Neural systems have the extraordinary capability to get importance from confused or inappropriate information and can be used to focus on the patterns and distinguish patterns which were extremely possible, either by people or other computer methods. An artificial neural network is a hook with set of nodes, as like the wide network range of neurons in the human brain. A prepared neural network can be conceived as an "expert" in the class of information which is provided examined. This expert can be utilized to present projections which states a new situations of concentration and respond for the "what if" questions. Neural systems utilize a group of processing nodes which are same to the neurons in the brain. These processing nodes were interlinked in a network which can identify the patterns in data once it is shown, i.e., as like people the network learns from practice. This identifies the neural networks from traditional computing programs which follows commands in a specific order. The customer analysis learning utilizes neural network, which is done according to the following kind of metrics. Those are

- Technology proficiency metrics.

- Employee proficiency metrics.

- Process efficiency metrics.

\subsection{TECHNOLOGY PROFICIENCY METRICS: IT SUFFICIENCY (\%)}

\subsubsection{Current Number of sCRM Supporting Function/ Necessary:}

Customer relationship management (CRM) software continue with a huge workload for business processes, specifically for the sales process. A CRM solution with its native integrates into key marketing technologies such as marketing automation which is created for a wonderful chance for small businesses and huge enterprises to do well. Now, businesses required to accurately control prospects, opportunities and current customers with good responsibility. Utilizing a CRM platform is a significant part in this strategy. CRM Features / Functionality List were provided as follows.

- Contact Management: This feature permits us to arrange the contacts into groups and into any context that we see it.

- Sales Team and Customer Opportunity Management: Measuring the chances which the sales team has with customers is an almost new feature that is now available for business. We can place the customers who were most likely to transform using this technology.

- Lead Management for determining high-quality leads: The technology now permits a business to define the good 
customers to follow up with, according to the demographic and psychographic factors.

- Reports and Dashboards: Users can view statistics visually by engaging the perspective through utilizing the customized reports and dashboards.

- Customizable Home Screen and Layouts: The UI of the program is apt to hold the visual perspective of everything which involves the home screen. Layouts can also be modified.

- Sales Analytics: Generate better sales campaigns in the future by examining the hard data of past campaigns.

- Mobile CRM including a Mobile App and Alerts: Take customer relationship management on a remote device by utilizing the mobile CRM programs. A user can also obtain the valuable alerts regarding the CRM program which is being controlled from a central location on a mobile device.

- Sales Force Automation: The CRM platform has the capability to automate specific form of sales which involves outgoing calls, follow up campaigns and the organization of data for more efficient campaigns.

- Sales Forecasting: A huge part of customer relationship management is defining a metric for success. Prediction lets us to know a reference point by which we can define whether our results were absolutely on par with the efforts.

- Sales Collaboration: Do business with the best co-workers via the collaboration features within your management program. You can draw the attention of more sales by arranging the people together who work well.

\subsubsection{Number of sCRM Supporting Functions:}

Executing dozens of various CRMs for different business sizes. We came to know that tons of features and functionalities should be conceived before buying and performing the customer relationship management system. But, it absolutely boils down to 2 key points. To choose the right CRM, you required to: 1) know entire available CRM features are, and 2) know which particular CRM functionality your team and organization requires.

\section{Monitoring Functions:}

- Emerging crisis identification: Crisis management is the process by which an organization proceeds with a confused and abrupt event that intimidates to affect the organization, its stakeholders, or the general public.

- Trend discovery/analysis: Trend Discovery controls the capital on behalf of investors who share our investment objectives of outstanding growth, non-correlated absolute returns and capital preservation. Our team has investment experience in long-short equity, venture capital and private equity.

- Customer opinions \& attitudes: The constant monitoring of a company's internal situation is the good way to avoid the undesirable situations like loss of productivity at work or the losing the valuable employees. Professional research can give the objective information and examine the personnel opinions and assist in finding the areas of the company that required enhancing.

- Buzz analysis: Buzz analysis is nothing but auditing the consumer responses to commercial services and products, in order to develop the marketing buzz surrounding a new or current offer. Alike the media monitoring, it is becoming very famous as a base for strategic insight development close to other forms of market research. Buzz monitoring includes verifying and examining of myriad online sources like internet forums, blogs, and social networks. Data can be given in real time that critical problems can be picked up directly. It is also comparatively economical distinguished to various market research tools and can usually trained the further product and service developments. Influence is a key question in buzz monitoring - it does this to a specific person and/or this specific piece of content and is it influencing others? So, the influence of a source is a significant thing in the buzz monitoring metric, which should be a reference point.

- Topic trends: A trending topic is a subject that experiences a rush in recognition on one or more social media platforms for a restricted time frame. Ecommerce businesses can validate the social media trends to identify what's holding consumer interest and exploit the existing conversation.

- Brands/products/firm names: a name which is provided to a product by the company that creates or sells it.

\section{Analytics functions:}

- Sentiment analysis: The process of computationally finding and segregating the opinions which is expressed in a piece of text, specifically to define nature of the writer's attitude towards a specific topic, product, etc. i.e., positive, negative, or neutral.

- Identification of key influencers: A key influencer is person who is active online and followed by your target audience. Competitors weren't considered here, but instead individuals who desirous the industry where our business continues in.

- Market/competitor analysis: Competitor analysis in market -ing and strategic management is identifying the strengths and weaknesses of existing and promising competitors. In marketing competitor analysis, we can utilize the strengths and weaknesses of our challengers and it is a crucial point in the marketing strategy.

- Frequent words analysis: In computational linguistics, a frequency list is a sorted list of words (word types) arranged together with their frequency, where frequency here commonly means the occurrence's count in a provided corpus, from which the rank, less meaningful, can be derived.

- Customer identification (demographics, geography): A Customer Identification Program (CIP) is a United States requirement, where financial institutions required to validate the personality of individuals who wish to conduct financial transactions with them and is a provision of the USA Patriot Act.

- Topic categorization: Text classification is a form of supervised learning, the set of possible classes were known/ defined in advance and don't change. Topic modeling is a form of unsupervised learning (akin to clustering), the set of possible topics are mysterious apriori. They are determined as part of the topic models creation. 
- Incident analysis: Incident analysis is a structured process for detecting what happened, how and why it happened, what can be done to minimize the risk of repetition and make care safer, and what was learned.

- Customer segmentation: Customer segmentation is the practice of segregating a customers into a set of individuals, who are common in a particular ways of marketing, like age, gender, interests and spending habits

\section{Strategic customer information availability ratio (\%):}

- Currently available SCRM customer information items/ideally available SCRM customer information items

\subsubsection{Employee Proficiency Metrics:}

- Skills assessment (specialist skills \& general proficiency) (\%): A workplace skills evaluation includes noticing the candidate as they execute their regular work, frequently over a period of time, and utilizes a variety of methods to gain an all-round picture of that person's existing abilities and future potential.

- Number of employees trained in SCRM.

- Training days/employee.

- Strategic job coverage ratio: The debt service coverage ratio computes how well a company is capable of paying its whole debt service. The ratio is determined as net income which is segregated according to the total debt service. A ratio of one or above is exhibitive that a company creates an enough earnings to entirely cover its debt responsibility.

\subsubsection{Process Efficiency Metrics:}

\section{Job efficiency metrics:}

- Agent productivity: Managers should compute the capacity of their employees to control the customer fulfillment levels, lower the cost structure and accomplish the profit growth. A low abandon rate relative to the historical or industry average usually represents the call center agents who were managing the customer calls effectively.

- Time per service job: Full-time employment is where a person who works less number of hours, this is determined as such by his/her employer. ... Companies usually demands from 35 to 40 hours per week to be determined as fulltime and hence suitable for merits.

- Service cases handled per customer service staff: Customer service is the arrangement of service to customers before, during and after a purchase. The understanding of success of such communication is based on employees "who can adapt themselves to the personality of the guest".

- Average handling time (adopted from cases): Average handle time (AHT) is a call center metric for the average duration of one transaction, typically computed from the customer's inauguration of the call and involves any hold time, talk time and based work which follow the transaction. AHT is a prime factor while deceiving the call center staffing levels.

- Issue resolution rate/time: For a service desk, first contact resolution (FCR) is the percent of contacts that are solved by the service desk on the first step of communication with the customer. For live calls or web chats, represents that the customer's problem is solved before they hang up the phone or end the chat session

- Rate of satisfied serviced customers (\%): It is a computation of manufacturing technique of the products and services provided by a company or surpass customer expectation. Customer fulfillment is determined as "the number of customers, or percentage of total customers, whose reported experience with a firm, its products, or its services (ratings) goes beyond the particular fulfillment goals."

\section{Acquisition Rate}

- New customer / total customer (per year);

\section{SCRM Customer Knowledge Creation}

- Number of registered SCRM customer knowledge by customer-facing employees;

- SCRM customer information Integration (\%),

- Number of service cases/resolved service case ratio

The above metrics would be computed regularly according to the customer relation management which is assured to raise the profitability of the customer handling.

\section{EXPERIMENTAL RESULTS}

Here, numerical computation of the proposed research methodology is performed in terms of different performance measures to examine the performance enhancement of the proposed and current research methodologies. The MATLAB simulation environment is utilized to execute the proposed research methodology. The performance measures conceived in this work were given as follows: "Accuracy, Sensitivity, Specificity, and Precision".

The performance evaluation of the proposed research method is conducted by using the large scale data set which is downloaded from the link, "https://datahub.io/dataset/evolution-anddevelopment-of-customer-lifetime-value". As the concept of customer relationship management theory has been accepted by modern society, customer lifetime value gradually has been awarded by the marketing scholars and business community. How to calculate and predict customer lifetime value has become a hot research field in the customer relationship management. This paper reviewed and summarized the definition of customer lifetime value, qualitative and quantitative studies. Then it elaborated the status quo of customer lifetime value model study and its shortcomings. Finally, it proposed some suggestions for future study based on the existing research results.

The proposed research methodology is executed in the MATLAB simulation environment which is computed for its performance over the performance metrics. The proposed method NN-SCRM and the existing methodologies CKM and SCRM were distinguished.

Accuracy: It is determined as degree of appropriate detecting of drug names which avails in the tweets. That is less false positive rate. The accuracy of the proposed system has to be high than the current approaches like IDM and SVM. The accuracy value is measured in terms of the drug prediction system's true positive, false positive, true negative and false negative values. The accuracy is computed as like: 


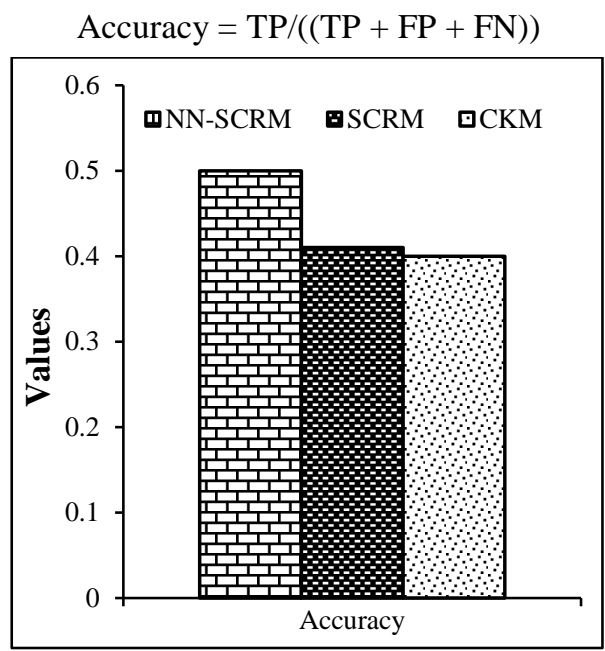

Fig.3: Accuracy comparison

The Fig.3 explains the accuracy metric in a graphical indication. This graph provides that the proposed research method is better than the current research methods. NN-SCRM is $22 \%$ better than SCRM and 25\% better than CKM.

Sensitivity: It is also known as true positive rate which is determined as the degree appropriately signifies the drug data items as positive. The example of a medical test utilized to find the disease, the sensitivity of the test is the proportion of people whose test result is positive for the people with disease. Mathematically, this can be represented as:

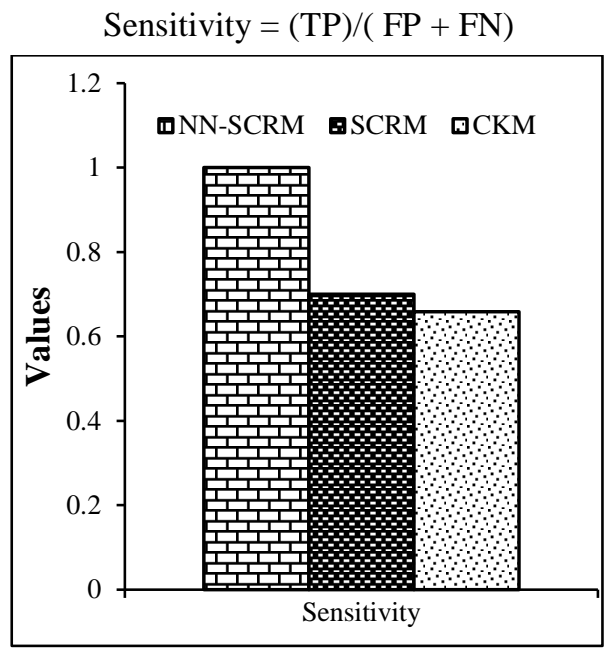

Fig.4. Sensitivity Comparison

The Fig.4 explains the sensitivity metric with a graphical indication. This graph provides that the proposed research method is better than the current research methods. NN-SCRM is $43 \%$ better than SCRM, 52\% better than CKM.

Specificity: It is also termed as true negative rate which is determined as the degree of exactly signifying non-drug data items. Conceive the sample of the medical test for diagnosing a disease. Specificity of a test and is the proportion of healthy patients who doesn't have disease, and their test results in negative. Mathematically, this can also be written as:

$$
\text { Specificity }=(\mathrm{TN}) /(\mathrm{TN}+\mathrm{FP})
$$

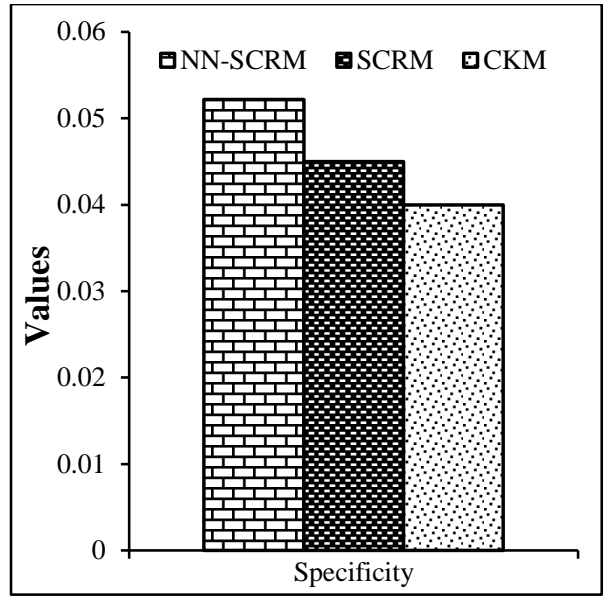

Fig.5. Specificity Comparison

The Fig.5 explains the specificity metric with a graphical indication. The graph gives that the proposed research method is better than the current research methods. NN-SCRM is $16 \%$ better than SCRM, $31 \%$ better than CKM.

Precision: It is the fraction of retrieved instances that are relevant to the data.

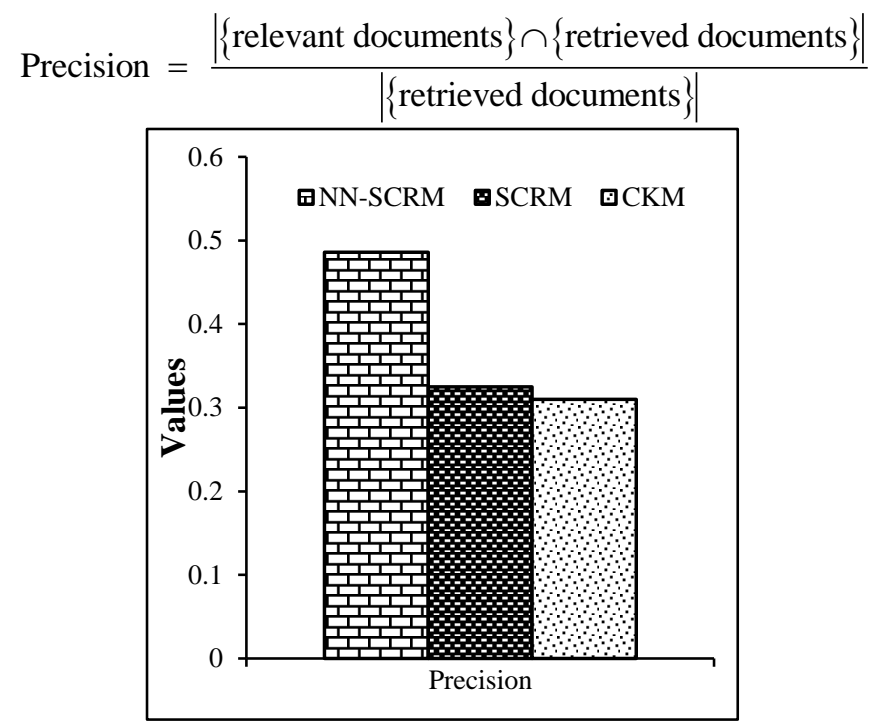

Fig.6. Precision Comparison

The Fig.6 explains the precision metric with a graphical indication. This graph denotes that the proposed research method is better than the current research methods. NN-SCRM is $50 \%$ better than SCRM, 57\% better than CKM.

\section{CONCLUSION}

SCRM joins the ability of the conventional customer relationship management (CRM) software to assist brands better employed by their customers. The, data acquired through CRM from the customers is explained in details in this stage via CKM via KM. In case cl., it could be alleged that the organization has accomplished good clarification become eventual in good knowledge. Knowledge about the customers, which in turn modifies the potential customers into identified ones within the 
organization. Furthermore, KM gives decent data regarding the abilities of the organization for the customers to instigate them for further assistance. The earlier identification of the customers generates helpful and real data for them. In the proposed research methodology, NN-SCRM is brought-in. This algorithm is utilized to examine the following factors by gathering the knowledge of the customer review information: "Predict the future, most profitable customers, maintaining quality of product development, customer life time value, identify customers and their products". This is done according to the information of the customer review, which, in turn, obtained from SCRM where the customers opinions disclosed by their comments regarding the product. This proposed research work is executed and examined in the MATLAB simulation environment from which it is confirmed that the proposed research framework tends to give the best output than the current CKM frameworks.

\section{REFERENCES}

[1] Colleen Cunningham and Il-Yeol Song, "A Taxonomy of Customer Relationship Management Analyses for Data Warehousing", Proceedings of $26^{\text {th }}$ International Conference on Conceptual Modeling in Tutorials, Posters, Panels and Industrial Contributions, Vol. 83, pp. 97-102, 2007.

[2] J. Wu, "Customer Relationship Management in Practice: A Case Study of Hi-Tech Company from China", Proceedings of International Conference on Service Systems and Service Management, pp. 1-6, 2008.

[3] B. Solis, "Engage: The Complete Guide for Brands and Businesses to Build, Cultivate, and Measure Success in the New Web", John Wiley \& Sons, 2010.

[4] J.H. Kietzmann, K. Hermkens, I.P. McCarthy and B.S. Silvestre, "Social media? Get Serious! Understanding the Functional Building Blocks of Social Media", Business Horizons, Vol. 54, No. 3, pp. 241-251, 2011.

[5] A. Payne and P. Frow, "A Strategic Framework for Customer Relationship Management", Journal of Marketing, Vol. 69, No. 4, pp. 167-176, 2005.

[6] A. Neely, M. Gregory and K. Platts, "Performance Measurement System Design: A Literature Review and Research Agenda", International Journal of Operations and Production Management, Vol. 15, No. 4, pp. 80-116, 1995.
[7] S. Gupta and V. Zeithaml, "Customer Metrics and Their Impact on Financial Performance", Marketing Science, Vol. 25, No. 6, pp. 718-739, 2006.

[8] F.F. Reichheld, "The One Number You Need To Grow", Harvard Business Review, Vol. 81, No. 12, pp. 46-55, 2003.

[9] D.L. Hoffman and M. Fodor, "Can You Measure the ROI of Your Social Media Marketing?”, MIT Sloan Management Review, Vol. 52, No. 1, pp. 41-49, 2010.

[10] B.D. Weinberg and E. Pehlivan, "Social Spending: Managing the Social Media Mix", Business Horizons, Vol. 54, No. 3, pp. 275-282, 2011.

[11] D. Chauvel and C. Despres, "A Review of Survey Research in Knowledge Management: 1997-2001", Journal of Knowledge Management, Vol. 6, No. 3, pp. 207-223, 2002.

[12] S.H. Liao, "Knowledge Management Technologies and Applications-Literature Review from 1995 to 2002", Expert Systems with Applications, Vol. 25, No. 2, pp. 155-164, 2003.

[13] M. Du Plessis, "Knowledge Management: What makes Complex Implementations Successful?", Journal of Knowledge Management, Vol. 11, No. 2, pp. 91-101, 2007.

[14] Z. Guo and J. Sheffield, "A Paradigmatic and Methodological Examination of Knowledge Management Research: 2000 to 2004”, Decision Support Systems, Vol. 44, No. 3, pp. 673-688, 2008.

[15] Z. Ma and K.H. Yu, "Research Paradigms of Contemporary Knowledge Management Studies: 1998-2007”, Journal of Knowledge Management, Vol. 14, No. 2, pp. 175-189, 2010.

[16] A. Serenko, N. Bontis, L. Booker, K. Sadeddin and T. Hardie, "A Scientometric Analysis of Knowledge Management and Intellectual Capital Academic Literature (1994-2008)", Journal of Knowledge Management, Vol. 14, No. 1, pp. 3-23, 2010.

[17] D.P. Wallace, C. Van Fleet and L.J. Downs, "The Research Core of the Knowledge Management Literature", International Journal of Information Management, Vol. 31, No. 1, pp. 14-20, 2011.

[18] Y.K. Dwivedi, K. Venkitachalam, A.M. Sharif, W. AlKaraghouli and V. Weerakkody, "Research Trends in Knowledge Management: Analyzing the Past and Predicting the Future", Information Systems Management, Vol. 28, No. 1, pp. 43-56, 2011.

[19] M.R. Lee and T.T. Chen, "Revealing Research Themes and Trends in Knowledge Management: From 1995 to 2010", Knowledge-Based Systems, Vol. 28, pp. 47-58, 2012. 